\title{
NILAI - NILAI KEARIFAN LOKAL GONG WANING PADA MASYARAKAT ETNIS SIKKA KROWE SEBAGAI SUMBER PENDIDIKAN KARAKTER
}

\author{
Yosefa Lemianti ${ }^{1}$, Gisela Nuwa ${ }^{2}$, Petrus Kpalet ${ }^{3}$ \\ IKIP Muhammadiyah Maumere \\ e-mail: 1 lenianti1994@gmail.com, ${ }^{2}$ gustavnuwa123@gmail.com, ${ }^{3}$ picekpalet@gmail.com
}

\begin{abstract}
Abstrak
Tujuan penelitian ini untuk mengetahui nilai-nilai yang terkadung dalam gong waning dan upaya untuk menjaga nilai-nilai kearifan lokal pada masyarakat Sikka krowe sebagai sumber pendidikan karakter. Metode yang digunakan dalam penelitian ini adalah metode deskriptif kualitatif yaitumenganalisis data deskriptif dengan cara memaparkan dan mendeskripsikan sesuatu yang ada. Penelitian ini menggunakan prosedur pengumpulan data adalah: Observasi, Wawancara, dan dokumentasi. Hasil penelitian dapat diketahui beberapa nilai gong waning seperti: Nilai Budaya, Nilai Ungkapan Syukur, Nilai Saling Menghargai, Dan Nilai Harmonis. Adapula upaya untuk menjaga nilai-nilai kearifan lokal pada masyarakat Sikka krowe sebagai sumber pendidikan karakter seperti:Upaya Partisipasi,Upaya Edukasi,Kebersamaan,dan Menanamkan Rasa Cinta Terhadap Kearifan Lokal Pada Masyarakat (Khususnya Generasi Muda Sikka krowe).Dengan memahami berbagai nilai-nilai yang terkandung dalam gong waning maka Masyarakat Sikka krowe diminta untuk melestarikan tradisi-tradisi nenek moyang yang merupakan obyek pemajuan kebudayaan agar tidak punah.
\end{abstract}

Kata kunci: Kearifan Lokal, Gong Waning Dan Pendidikan Karakter

\begin{abstract}
The purpose of this study was to determine the values contained in gong waning and efforts to maintain the values of local wisdom in the sikka krowe community as a source of character education. The method used in this research is a qualitative descriptive method that is analyzing descriptive data by describing and describing something that exists. This research uses data collection procedures: Observation, Interview, and documentation, Value of Gratitude, Value of Mutual Respect, and Harmonious Value. There are also efforts to maintain the values of local wisdom in the Sikka krowe community as a source of character education such as: Participation Efforts, Educational Efforts, Togetherness, and Instilling Love to Local Wisdom in the Community (Especially Sikka krowe Young Generation). By understanding the various values contained in gong waning, the Sikka krowe community is asked to preserve the traditions of the ancestors who are objects of cultural advancement to avoid extinction.
\end{abstract}

Keywords: Local Wisdom, Gong Waning and Character Education 


\section{Pendahuluan}

Kearifan lokal diartikan sebagai suatu bentuk pengetahuan asli dalam masyarakat yang berasal dari nilai luhur budaya setempat untuk mengatur tatanan hidup masyarakat [1]. Kearifan lokal sebagai cerminan dari hukum yang hidup dalam masyarakat sehingga perlu dilihat eksistensi yuridis kearifan lokal dalam peraturan perundang-undangan No. 32 Tahun 2009 [2] sebagai nilai-nilai luhur yang berlaku dalam tata kehidupan masyarakat untuk antara lain melindungi dan mengelola lingkungan hidup secara lestari.

Etnis Sikka krowe adalah komunitas adat yang berada di Kabupaten Sikka, di Flores Timur Tengah, Pulau Flores, Nusa Tenggara Timur. Etnis Sikka Krowe dianggap sebagai salah satu dari etnis Mukang. Etnis Mukang terdiri dari 4 suku yaitu suku Sikka, Suku krowe, Suku Mukang dan Suku Muhang [3]. Masing-masing etnis memiliki irama musik gong waning yang berbeda-beda, dalam etnis Sikka krowe terdapat empat irama musik gong waning diantaranya irama Todu,irama Glebak,irama Bladuba badan irama Leke.

Kearifan lokal adalah identitas atau kepribadian budaya sebuah bangsa yang menyebabkan bangsa tersebut mampu menyerap, bahkan mengolah kebudayaan yang berasal dari luar/bangsa lai menjadi watak dan kemampuan sendiri [4]. Identitas dan kepribadian tersebut tentunya menyesuaikan dengan pandangan hidup masyarakat sekitar agar tidak terjadi pergesaran nilai-nilai. Kearifan lokal adalah salah satu sarana dalam mengolah kebudayaan dan mempertahankan diri dari kebudayaan asing yang tidak baik.

Keberadaan alat musik tradisonal gong waning sudah cukup lama di kalangan warga kabupaten Sikka. Jauh sebelum adanya gong waning, warga Sikka memainkan alat musik tradisonal dari bilah bambu yang nadanya sama dengan Gong Waning yang ada sekarang. alat musik itu bernama "wala". Wala ini terbuat dari bambu. Setelah wala, berganti dengan letor. Letor adalah alat music tradisonal yang dimainkan dengan cara dipukul, terbuat dari kayu atau bambo yang dibuat sedemikian rupa hingga dapat menghasilkan bunyi yang menyerupai gong waning. Belakangan baru masyarakat mengenal gong. Gong Waning yang ada saat ini hanya berubah bentuk dan nama dari wala dan letor. Dalam hal ini, iramalah yang menjadi ciri khas musik tradisional warga Sikka. "Walaupun pakai gong dan waning, tetap iramannya dimainkan sama, Bunyinya juga tetap sama, Gong Waning itu terdiri atas tiga jenis instrumen utama yaitu, gong, waning, dan peli anak/sa'ur.

Pendidikan karakter merupakan rangkaian, sikap, perilaku, motivasi, dan keterampilan yang melekat dan menjadi ciri individual seorang. Meski berersifat pribadi, karakter dipengaruhi oleh konteks lingkungan sosial budaya dan berproses secara cair. Artinya, karakter berkembang dalam proses yang berlangsung secara seumur hidup yang melibatkan keseluruhan formasi sosial masyarakat, seperti lingkungan keluarga, lingkungan lembaga pendidikan, dan lingkungan sosial masyarakat [5].

\section{Metode Penelitian}

Metode yang digunakan adalah deskriftif kualitatif sehingga memudahkan proses pengumpulan data dan analisis data akan lebih terarah pada permasalahan yang sudah ditentukan sebelumnya [6]. Penelitian dengan tipe deskriftif adalah penelitian yang dimaksudkan untuk mengumpulkan informasi atau gejala yang ada yaitu keadaan menurut apa adanya pada saat penelitian dilakukan. Sumber data yang digunakan dalam penelitian ini adalah data primer adalah data yang diperoleh langsung dari informan. sedangkan data sekunder adalah data yang tidak langsung memberikan data kepada pengumpul data misalnya :buku-buku literatur dan lain sebagainya teknik pengumpulan data 
yang digunaka peneliti adalah observasi, wawancara, dan dokumentasi. Teknik analisis data yaitu reduksi data, model data dan Penarikan dan Verifikasi Kesimpulan.

\section{Hasil dan Pembahasan}

Nilai-nilai yang terkandung dalam gong waning pada Masyarakat Etnis Sikka krowe adalah sebagai berikut:

\section{a) Nilai Budaya}

Budaya gong waning pada masyarakat Sikka krowe terbentuk karena kepedulian dan keprihatinan oleh para pemuda Sikka krowe, mereka ingin mempertahan dan tetap melestarikan adat dan budaya warisan nenek moyang atau para leluhur. Budaya gong waning pada masyarakat Sikka krowe ini masih terus dilestarikan dan dijaga keberadaannya.salah satu bentuk pelestarian tersebut terlihat dari penggunaan dan fungsinya.

Gong waning tidak hanya digunakan sebagai pengiring upacara saja,namun juga sering ditampilkan sebagai pengiring seni tari diberbagai acara festival budaya maupun pertunjukan seni daerah. Selain itu berbagai kreasi dan variasi juga sering dilakukan, namun tetap disesuaikan dengan gerak tari ditampilkan. Nilai budaya Gong waning yang sudah turun temurun ada pada masyarakat Sikka krowe. budaya ini terbentuk dari banyak unsur salah satunya adalah sistem kesenian

\section{b) Nilai Ungkapan Syukur}

Setiap upacara adat (upacara syukuran) lainnya yang masyarakat Sikka krowe laksanakan merupakan sebuah bentuk doa, harapan maupun ucapan syukur kepada yang Maha Kuas atas segalah yang mereka terima, oleh karena itu upacara yang mereka lakukan selalu dilengkapi dengan iringan musik gong waning dan tarian yang merupakan simbol atau wujud ungkapan syukur kepada Tuhan. Nilai ungkapan syukur merupakan salah satu nilai yang bertujuan untuk mengungkapkan rasa berterimakasih kepada Tuhan atas segalah limpahan yang diberikan-Nya.

\section{c) Nilai Saling Menghargai}

Nilai saling menghargai merupakan salah satu tindakan yang dilakukan sapaya kita juga bisa dihormati dan dihargai seperti kita menghormati dan menghargai tamu-tamu yang akan datang. Gong waning biasanya dimainkan pada saat penjemputan tamu-tamu asing dan tamu terhormat. Dalam acara penjemputan tamu nilai saling menghargai ini sangat penting untuk diterapkan sebagai bentuk penghormatan kepada tamu baru yang hadir di sebuah kampung.

\section{d) Nilai Harmonisasi}

Dalam sebuah upacara para penabuh bebas untuk menentukan jenis irama yang mereka inginkan, namun untuk pertunjukan semuanya mengikuti pola gerakan para penari. dalam irama musik Gong Waning sesungguhnya hanya salah-satu instrument yang berperan penting yaitu; Waning Ina (Gendang yang berukuran besar). Instrument ini berfungsi untuk memberikan kode peralihan, melakukan penambahan pola-pola tertentu sehingga sesuai dengan gerak tari. Khusus untuk instrument gong, teknik tabuhannya tetap sama atau tetap pada aturan yang sudah ada. Jika ada instrument lain yang ikut membuat pola-pola baru agar sesuai dengan gerak tari, itu adalah instrument Saur.

Dunia seni tari perubahan dari satu irama ke irama yang lain tanpa mengunakan kode peralihan sedangkan dalam pertunjukan digunakan kode peralihan. Ini dilakukan agar para penari tidak melakukan kesalahan saat menari.untuk menyesuaikan pola gerakan-gerakan dalam tarian 
yang sudah digarap para pemusik biasanya keluar dari aturan atau pakem yang sudah ada, dan menambahkan pola tabuhan baru, sehingga sesuai dengan gerakan penari. Para pemusik mulai memperhatikan keras-lirihnya tabuhan, sesuai dengan gerakan yang dilakukan para penari. Ini agak berbeda jika musik Gong Waning dalam upacara mereka tidak terlalu memperhatikan keraslirihnya suara musik tersebut.

Harmonisasi antara penabuh musik dan penari merupakan cerminan kehidupan yang perlu terus dijaga keseimbangannya. Harmonisasi irama dan tarian memiliki nilai yang paling dalam yaitu kehidupan manusia mesti menjaga keseimbangan relasi antara Tuhan, sesama, dan terhadap alam semesta.

Budiyono dan Yoga Ardian Feriandi [7], dalam penelitiannya menemukan nilai-nilai kearifan lokal budaya Jawa sebagai sumber pendidikan karakter yaitu Aja Dumeh, Tepa selira, Mawas Diri, Budi Luhur, Sikap Wani Tombok, Mendhem Jero Mikul Dhuwur, Sifat Gemi, Nastiti dan Ngati-ati Sifat Gemi Jer Basuki Mawa Beya Ajining Dhiri Saka Obahing Lathi.

Antara budaya Jawa dengan gong waning pada etnis Sikka Krowe sama-sama menggali nilai-nilai kearifan lokal sebagai sumber pendidikan karakter. Selain itu juga keduanya mencoba mengangkat kasana budaya meskipun lokus dan subyeknya berbeda. Semua nilai budaya yang diangkat merupakan representasi dari unsur-unsur budaya yang kaya akan makna dibaliknya. Memang jika dicermati dengan baik, nilai budaya merupakan bagian yang tidak bisa dipisahkan dari kehidupan manusia itu sendiri [8].

Dalam etnis Sikka krowe juga terdapat nilai-nilai budaya terutama dalam ritus poto wua ta 'a (peminangan). Di dalamnya memiliki nilai ungkapan syukur, menjaga kesucian, dan harus hidup rukun. Pada etnis Sikka krowe memiliki banyak nilai budaya yang bisa dijadikan rujukkan dalam pengembangan pendidikan karakter. Dengan demikian kearifan lokal Etnis Sikka Krowe merupakan bagian integral dari kebudayaan nusantara Bangsa Indonesia [9]. Nilai - Nilai Kearifan Lokal Gong Waning Pada Masyarakat Etnis Sikka Krowe Sebagai Sumber Pendidikan Karakter lebih menekan pada Nilai Budaya karena Masyarakat Sikka Krowe diminta untuk melestarikan tradisi-tradisi nenek moyang yang merupakan obyek pemajuan kebudayaan agar tidak punah salah satunya adalah Gong Waning.

\section{Eksistensi Gong Waning: Sebuah Upaya Untuk Tetap Eksis}

Upaya untuk menjaga nilai kearifan lokal pada masyarakat Sikka Krowe sebagai sumber pendidikan karakter

\section{a) Partisipasi}

Partisipasi merupakan keterlibatan masyarakat dalam keikutsertaan dalam melakukan suatu kegiatan yakni ikut terlibat dalam bentuk penyampaian saran dan pendapat, barang, keterampilan, bahan dan jasa. Hal yang sama pula di kemukakan oleh Faslidan Supriadi [10], bahwa Pelestarian merupakan upaya untuk membuat sesuatu yang tetap atau tidak berubah, Pelestarian bisa juga didefinisikan sebagai upaya untuk mempertahankan sesuatu upaya tetap sebagaimana adanya Partisipasi dapat sjuga berarti bahwa kelompok mengenal masalah mereka sendiri, mengkaji pilihan mereka, membuat keputusan, dan memecahkan masalahnya. Terkait dengan temuan penelitian di lapangan bahwa upaya partisipasi dalam Menjaga Nilai-Nilai Kearifan lokal pada masyarakat Sikka Krowe sangat tinggi dilihat dari kesadaran masyarakat Sikka Krowe untuk mengikut kegiatan kebudayaan. 


\section{b) Edukasi}

Edukasi atau disebut juga pendidikan merupakan segala upaya yang direncanakan untuk mempengaruhi orang lain, individu kelompok, atau masyarakat sehingga mereka melakukan apa yang diharapkan oleh pelaku pendidikan [11]. Edukasi merupakan proses belajar dari yang tidak tahu menjadi tahu. Terkait dengan temuan penelitian di lapangan bahwa dalam menjaga pelestarian kearifan lokal yang ada pada masyarakat Sikka Krowe, maka figur-figur yang mempunyai pengalaman yang ada selau mendidik, membimbing dan memberikan memotivasi terhadap generasi penerus Sikka Krowe.

\section{c) Kebersamaan}

Masyarakat Sikka Krowe memiliki kesadaran penuh bahwa dia tidak dapat hidup sendiri dan tanpa bantuan dari orang lain. Secara psikologis setiap insan membutuhkan komunikasi dengan orang lain baik dengan sesama anggota keluarga dengan tetangga, dengan masyarakat dalam komunitas bernegara. Sejak zaman dahulu sampai sekarang masyarakat Sikka Krowe tetap membutuhkan rasa keberamaan, rasa kekeluargaan dan rasa saling peduli, rasa tolong menolong, Aktivitas gotong royong yang ada dalam masyarakat Sikka krowe membentuk mentalitas bangsa menjadi lebih berkarakter dan melahirkan banyak nilai-nulai luhur yang bermanfaat bagi kehidupan. Begitupula dengan budaya gong waning yang ada pada masyarakat Sikka krowe, mencerminkan kebersamaan yang tumbuh dalam lingkungan masyarakat. kebersamaan terjalin dalam gotong royong sekaligus melahirkan persatuan antar anggota masyarakat, dengan persatuan yang ada masyarakat lebih kuat dan mampu menjaga nilai-nilai kearifan lokal yang ada agar bertahan dan tidak punah.

d) Menanamkan Rasa Cinta Terhadap Kearifan Lokal Pada Masyarakat (Khususnya Generasi Muda Sikka Krowe)

Budaya sendiri merupakan kebiasaan yang ada dalam suatu masyarakat dan menjadi ciri khusus atau pembeda suatu daerah dengan daerah lain, kebiasaan disuatu daerah tersebut dilakukan dalam jangka waktu yang lama (diwarsikan secara turun-temurun) sehingga menjadi suatu kebuadayaan. Lunturnya rasa memiliki,rasa menghargai dan kebanggaan generasi muda terhadap kearifan lokal bisa menjadi pemicu terkikisnya suatu kebudayaan yang ada pada masyarakat. Maka dari itu perlu memberi pemahaman pada generasi muda untuk cinta akan kearifan lokal itu sendiri. Orangtua tidak perlu lagi pertanyakan apa mereka cinta atau tidak dengan budayanya, karena kemungkinan sudah pasti mereka sangat cinta dan bangga dengan budayanya. Generasi muda memiliki rasa cinta yang sama dengan para pendahulunya, maka dari itu mengkaderisasi generasi muda untuk cinta dengan budaya sendiri sangat penting dalam menjaga eksistensi kebudayaan dalam suatu bangsa.

\section{Kesimpulan}

Masyarakat Etnis Sikka Krowe kaya akan kearifan lokal salah satunya adalah Gong waning. Gong Waning merupakan salah satu elemen dasar dalam membangun pendidikan karakter yang baik sehingga masyarakat etnis Sikka Krowe dimintah untuk melestarikan tradisi-tradisi nenek moyang yang merupakan obyek pemajuan kebudayaan agar tidak punah.Nilai yang terkandung dalam gong waning perlu dilestarikan agar tidak punah dan hilang.Nilai-nilai tersebut adalah:nilai budaya,nilai ungkapan syukur,nilai saling menghargai dan nilai harmonisasi.

Adapula upaya untuk menjaga nilai kearifan lokal pada masyarakat Sikka krowe sebagai sumber pendidikan karakter adalah upaya partisipasi, upaya edukasi kebersamaan dan menanamkan rasa cinta terhadap kearifan lokal pada masyarakat (khususnya generasi muda Sikka Krowe). 


\section{Daftar Pustaka}

[1] Sibrani, Robert. 2012. Kearifan lokal: hakikat, peran, dan metode tradisi lisan. Jakarta: Asosiasi Tradisi Lisan (ATS).

[2] UU NO.20 Tahun 2003 Tentang Sistem Pendidikan Nasional

[3] Nuwa, Gisela. 2020. Lokal Geniu Po’o. Maumere: IKIP Muhammadiyah Maumere.

[4] Wibowo. 2015. Pendidikan Karakter Berbasis Kearifan Lokal Di Sekolah. Yogyakarta: Pustaka Pelajar.

[5] Kurniawan, Syamsul, Pendidikan Karakter Dalam Islam Pemikiran Al-Ghazali Tentang Pendidikan Karakter Nak Berbasis Akhlaq-Karimah. Tadrib, Tahun 2017, Vol. 3 No. 2. Hal. 198-2012.

[6] Arikunto, S. 2010. Presedur Penelitian Suatu Pendekatan Praktik.J akarta. Rineka Cipta.

[7] Yoga A. F. dan Budiyon. Menggali Nilai Nilai Kearifan Lokal Budaya Jawa Sebagai Sumber Pendidikan Karakter. Prosiding SNBK Tahun 2017, Vol. 1, No.1 Madiun: FKIP Universitas PGRI. Hal. 92-103.

[8] Koentjoroningrat. 2012. Pengantar Ilmu Antropologi. PT. Rineka Cipta. Jakarta

[9] Nuwa, Gisela, Ahmad Yani. Analisis Struktur Batin Syair Adat Pada Masyaraka Sikka Krowe Dalam Tradisi Poto Wua Ta'a Di Kabupaten Sikka Nusa Tenggara Timur. Mabasan, Tahun 2019, Vol. 13, No. 1. hal. 60-76.

[10] Supriadi. 2011. Strategi Pembangunan Kelompok Masyarakat. Yogyakarta: Pustaka Pelajar.

[11] Notoadmojo, Soekidjo, 2003. Pengembanga nsumber Daya Manusia. Jakarta: PT. Rineka Cipta 